The G reening of Social Capital:

An Examination of Land-Based Groups in Two Vermont Counties

by

\author{
Andrew Savage \\ Jonathan Isham \\ Christopher McG rory Klyza
}

January 2004

MID D LEBURY COLLEGE ECONO MICS DISCUSSION PAPER NO. 03-06R

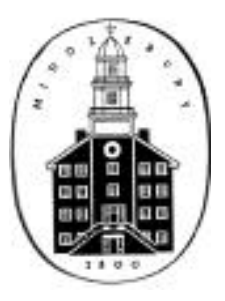

DEPARTMENT OF ECONOMICS

MIDDLEBURY COLLEGE

MIDDLEBURY, VERMO NT 05753

http:/ / www.middlebury.edu/ econ 


\title{
The Greening of Social Capital: An Examination of Land-Based Groups in Two Vermont Counties*
}

\author{
Andrew Savage, Jonathan Isham, and Christopher McGrory Klyza \\ Middlebury College
}

January 2004

Forthcoming in Rural Sociology

\begin{abstract}
By undertaking a census of all agricultural, outdoor recreational, and environmental groups (land-based groups) in two adjacent counties in Vermont, we demonstrate the dramatic increase of local environmental groups in the last 15 years. Building on the methodologies of Kempton et al. (2001), we first show that official lists of nonprofit groups-from the Vermont Secretary of State, the Internal Revenue Service, and local grassroots directories-significantly undercount local environmental groups. Second, we show that since the mid-1980s, the number and membership roles of local autonomous environmental groups have grown rapidly relative to all other types of local and non-local land-based groups in these counties. This article provides preliminary evidence of the recent "greening of social capital.”
\end{abstract}

Keywords: civic engagement, social capital, environmental policy

JEL Codes: Z13; Q28

\footnotetext{
* This is a dramatic revision of Savage, Isham, and Klyza (2002), which was presented at the Annual Meeting of the New England Political Science Association in May 2002. We thank Judy Layzer and other participants at the conference for helpful comments on the previous draft. We also thank Marc Aboglioli, Christopher Bosso, David Colander, Willet Kempton, Robert Pekkanen and William Shutkin for their feedback and suggestions.
} 


\section{The Greening of Social Capital: An Examination of Land-Based Groups in Two Vermont Counties}

Recent scholarship on civic engagement and social capital in the United States overlooks the rising influence of local environmental groups in the United States (Putnam 2000; Skocpol, Ganz, and Munson 2000). Indeed, Robert Putnam writes in his influential Bowling Alone: "The gentlest verdict on the claim of growing grassroots environmental activism is "not proved"” (Putnam 2000:161). Recent empirical work, however, begins to demonstrate the significance of such local environmental groups. Based on a comprehensive census of environmental groups in the Delmarva Peninsula and in North Carolina, Kempton et al. (2001) show that membership in environmental groups is seven to ten times higher than documented by even the best group directory. A recent household survey by Holland (2002) reveals that 18.2 percent of North Carolinians report that they are members of a group that works on environmental issues, higher than all other reported issue groups (including social justice, women’s rights, Christian, and civil rights).

We expect that in Vermont local environmental groups are flourishing as well. Over the last two centuries, the structural shift from an agricultural to a service economy in the United States has not only altered what we do for a 
living, but also it has altered the nature of our civic engagement. In northern New England, for example, few citizens still gather at Grange halls or write letters to the agricultural press as they did in the late 1800s (Judd 1997). By contrast, a relatively large number of citizens are now actively engaged in cleaning up their local watershed (Lubell et al. 2002). Our civic engagement is still fashioned by our relationship to the landscape, but the nature of this civic engagement in rural America has been transformed. This article is an empirical analysis of land-based groups in two counties in Vermont. Through this study we seek to enumerate all agricultural, outdoor recreational, and environmental groups in two adjacent counties in Vermont in order to better understand these groups and to begin to determine what role, if any, they play in generating social capital in this part of northern New England. We think that local environmental groups are a major force in Vermont, leading to what we call the "greening of social capital."

Our analytical strategy is as follows. We discuss how the concept of social capital can be used to evaluate changes in rural settings. We then briefly describe Vermont's economic and social context. We define land-based groups and two other group classifications—-local, state, or national groups; and autonomous groups or chapters — and then detail our census methodology. We use the census data to illustrate the different characteristics of land-based groups. Finally, we conclude by discussing the role of land-based groups, especially environmental groups, in social capital in rural northern New England. 


\section{Using the Concept of Social Capital to Analyze Rural Places}

In a recent article in this journal, Emery Castle assesses the relevance of the term social capital for rural studies (Castle 2002). Castle reviews the recent prominent literature on social capital and addresses diverse critiques of the term, including those on conceptual ambiguity and measurement. He concludes that the term has the potential to be useful if it is considered neither as an overarching social theory nor as a source of normative goals, but rather as an interdisciplinary concept (Castle 2002:346). Our work is embedded within the ideas presented by Castle, namely by examining the existence of rural groups that are the precursors to social capital formation and by examining chronological aspects of group formation. ${ }^{1}$

\section{Defining and Measuring Social Capital}

The premise of the concept of social capital begins with the observation that recurring and patterned social interactions among a set of individuals-in their neighborhoods, their churches and schools, and their local organizationsgenerate networks and norms that affect a wide range of economic and social decisions. In this article, we adopt the definition and approach of Woolcock (2002:22), who defines social capital as "the norms and networks that facilitate collective action" and argues that the term makes most sense when it is understood as a relational (i.e., sociological), rather than psychological or political, variable since "the best and most coherent empirical research on 
social capital, irrespective of discipline [emphasis added], has operationalized it as a sociological variable” (Woolcock 2002:22).

In our analysis of land-based civic engagement in Vermont, the foundation of our research is the collection of data on the quantity and quality of organizations in a largely rural setting. ${ }^{2}$ We link environmental group membership with social capital by following the lead of Putnam's major study on the transformation of social capital in the United States. Putnam used 14 state-level measures of social capital to construct (using principal components analysis) a single Social Capital Index. Of those 14, five are "measures of community organizational life” (Putnam 2000:291):

- $\quad$ Civic and social organizations per 1,000 population

- $\quad$ Mean number of group memberships

- $\quad$ Mean number of club meetings attended last year

- $\quad$ Served on committee of local organization last year (percent)

- $\quad$ Served as officer of some club or organization in last year (percent). ${ }^{3}$

Consistent with Putnam's measures, we use (as detailed below) measures of the number of different groups, core membership in groups, and basic membership in groups to assess different forms of social capital in these two counties.

We believe that these are good measures of networks that facilitate collective action in rural Vermont. For example, core members of local environmental groups are undoubtedly important for producing social capital. 
We identify core members by the following range of behaviors: members who are "most active, who attend meetings or participate in events or activities" (Kempton et al. 2001:565). Their membership roles, most often as board members and officers, are critical for forming strong networks among group members, between groups, and with individuals in positions of power. ${ }^{4}$

\section{Vermont, Land-Based Groups, and Social Capital}

One would rightfully expect social capital in Vermont to be as strong as just about anywhere in the United States. In the last 100 years, during its economic and social transition away from dependence on agriculture, Vermont has remained the most rural state in the nation. Building on its rich tradition of citizen participation in small town government, it has the highest number of nonprofit groups per capita in the United States: 3.6 per 1,000 inhabitants (Putnam 2000:292). Indeed, Vermont ranks at the top of most state-level measures of social capital (Knack 2002; Putnam 2000).

Nevertheless, in his comprehensive study of the decline of social capital in the United States, Putnam reports that "even in the tiny, civic-minded hamlets of pastoral Vermont, attendance at town meetings fell by nearly half between the early 1970s and the late 1990s” (Putnam 2000:247). As in much of Putnam's study, the inference to be drawn from such statements seems to be clear: less activity in traditional community settings, less social capital.

While acknowledging the remarkable decline since the 1960s in most traditional social and civic groups (e.g., the Masons, the Grange, and the Independent Order of the Odd Fellows), we believe that the decline of social 
capital in rural areas is not as definitive as Putnam suggests. As the relationship between humans and the landscape has changed, so has the nature of rural social capital. For example, in the 1800s, agricultural and outdoor recreational groups in Vermont and the rest of northern New England played an active role in local, state, and national conservation policy making (Judd 1997). In the last half of the 1900s, agricultural groups have grown much less influential as the number of Vermonters engaged in agriculture declined. But rather than becoming disengaged from social and civic activity, we think that Vermonters are investing in new forms of social capital building. They are joining and participating in new environmental groups-the greening of social capital.

In many ways, Vermont provides the most fertile possible soil for the growth of environmental groups. In addition to being a national leader in participatory local government and nonprofit activity, Vermont is also recognized as a leader in protecting the environment. In the Institute for Southern Studies “Gold and Green” indices of economic and environmental performance, Vermont ranked first on the "green scale" in both 1994 and 2000 (Institute for Southern Studies 2000). The 1991-1992 Green Index ranked Vermont third in the nation (Lester 1994).

Accordingly, it comes as no surprise that Vermont has many effective state-based environmental groups-mostly based in Montpelier (the state capital) or Burlington (the largest city in the state)—-that are significantly affecting state-level environmental policy (VNRC 2000). But most of these 
groups, which have paid staff and memberships in the thousands, can in fact be characterized as tertiary groups with members mainly based on "checkbook affiliation” (Putnam 2000:158). We note that, due to Vermont's relatively small population (approximately 613,000, the second smallest in the United States) and geographic size, this characterization could be challenged: it is likely that these state-based groups do contribute to the generation of social capital in Vermont (Kimberly 2002; Wollebaek and Selle 2002). Nevertheless, in the analysis that follows, such groups will be treated separately from the local land-based groups. We do this in order to emphasize the rise of active local environmental groups.

\section{Research Methodology}

Our census of land-based groups was conducted in Addison and Washington Counties. We selected Addison County, which has 23 rural towns and a population of 36,000 , because of our previous research in the area and its geographic proximity. We selected Washington County, which has 19 towns and a population of 58,000, because it consists of both rural regions and a more densely populated area: it includes the state capital Montpelier and the adjacent city of Barre, which together comprise the third largest urban area in the state. Addison County, which includes the central part of the Champlain Valley on the shore of Lake Champlain, has rich soils that are ideal for agriculture. Washington County, which includes the central part of the Green Mountains, has a well developed skiing and recreationally oriented tourist industry. All 
told, the 42 towns in these two counties give a representative snapshot of the ecological and cultural contours of Vermont's 249 towns in 15 counties (Klyza and Trombulak 1999). ${ }^{5}$

\section{Group Classifications and Definitions}

The focus of this article is land-based groups, which comprise three types of subgroups: agricultural groups, outdoor recreational groups, and environmental groups.

- An agricultural group is a self-named, voluntary collection of people (or member organizations) whose lives and livelihoods are directly connected to agriculture, farming, and farm animals.

Such groups typically focus on advocating political goals of farmers (e.g., chapters of the Grange and of the Farm Bureau) or on social and civic activities related to farming (e.g., chapters of the Grange and 4-H groups).

- An outdoor recreational group is a self-named, voluntary collection of people (or member organizations) who partake in a common set of recreational activities in the outdoor landscape.

The recreation must take place in a natural as opposed to human-made environment. Hence, a group of mountain bikers would fall into this category, a group of road bikers would not; a snowmobile club would count as an outdoor recreational group, a soccer club would not.

- An environmental group, adopting the definition of Kempton et al. (2001:561), "is a self-named, voluntary collection of people (or member organizations) who agree on some part of a view of the ethical 
or appropriate relationship between humans and the world around them, who communicate with each other about this topic, and who perform action in a particular venue in order to advance their view of it.”

Land-based groups, which focus on ethical, political, recreational, and social activities directly related to human interactions with the landscape, do not include trade associations or other groups focused primarily on an economic relationship to the land.

A second classification distinguishes local and nonlocal groups:

- A local group, again following Kempton et al. (2001:561), is based on "the social criteria of communication, direct participation, and shared venue, which typically but not necessarily imply geographical proximity of members.",6

- A nonlocal group is based on the political criteria of state, regional, national, or international boundaries, which typically but not necessarily imply geographical distance of members.

Our census includes all local land-based groups in Addison and Washington Counties and (as detailed below) four kinds of nonlocal groups: state-, regional-, national-, and international-level groups. For example, Forest Watch is a state-level group based in Montpelier that is dedicated to protecting Vermont's wilderness; the ElectroMagnetic Radiation Network is an international-level group based in Marshfield that is dedicated to lowering exposure to electromagnetic radiation throughout the world. 
Among local and nonlocal groups, a third classification distinguishes autonomous groups and chapters:

- An autonomous group is a self-formed and self-governed group that, though it may be part of larger networks or coalitions, is not subject to the formal by-laws of a nonlocal group.

- A chapter is typically but not necessarily a self-formed and selfgoverned group that, in addition to possibly being part of larger networks or coalitions, is subject to the formal by-laws of a nonlocal group of which it is a branch.

For example, the Watershed Center, which is dedicated to increasing land conservation and improving water quality in the Bristol area, is an autonomous local group. ${ }^{7}$ The Ducks Unlimited chapter of Vermont, which is headquartered in Bristol, is a state-level national chapter.

\section{The Creation of the Group Census}

We collected data on the history, membership, and objectives of every existing land-based group in these two counties. ${ }^{8}$ As we began, we compiled all available sources at our disposal from previous research (Isham and Polubinski 2002; Klyza and Trombulak 1999; Savage, Isham, and Klyza 2002), our classroom teaching, and our personal knowledge of these two counties. These sources included group directories (the Vermont Environmental Directory (VNRC 2000) and the Vermont Grassroots Directory (VPJC 2002)), local newspaper articles and weekly calendars, websites, and the local telephone book. To further expand our group list, we asked selected 
group leaders by phone whether they knew of other land-based groups. As we began the census, this question often produced several new groups. We also called or visited most town clerks and asked whether they knew of any additional groups. We also used the databases of the Vermont Secretary of State on registered nonprofits and the Internal Revenue Service (IRS) on Vermont “501(3)c’s.”

In our phone interviews with group leaders, we gathered specific information about each land-based group: the founding date, mission and activities, current membership numbers, current core membership numbers, operating budget, level of political activity, and extent of local partnerships with other groups. We adopted consistent data recording standards when group leaders gave incomplete responses. When a range of dates was given for the founding date, the mean date was used. When a range was given for membership or core membership, we chose the smaller number. For state-, national-, and international-based groups, only board directors were counted as core members. For school groups, only officers were counted as core members. For groups that are group federations—-for example, the Northern Forest Alliance—only board directors were counted as core and total members. When we could not contact anyone in a group that we knew existed, we gave the group zero membership (following Kempton et al. 2001). All told, these standards underestimated the number of members and core members in these groups. 


\section{The Nature of Land-Based Groups}

In this section, we use the data from our census to address four questions related to the nature of land-based groups in these two counties. How well do publicly available lists enumerate local and nonlocal land-based groups? How are autonomous groups and chapters distributed among agricultural, outdoor recreational, and environmental groups? How does the founding year differ among agricultural, outdoor recreational, and environmental groups? What is the current core and total membership among agricultural, outdoor recreational, and environmental groups?

\section{Publicly Available Lists of Land-Based Groups}

As explained in the methodology section, we used databases from the Vermont Secretary of State, the IRS, and two published directories to help create our census. As illustrated in Table 1, none of these publicly available sources comes close to fully capturing the extent of local land-based groups in Vermont. The best source, the Secretary of State's list of registered nonprofits, listed just 32 of the 95 local land-based groups in Addison County and 40 of the 90 local groups in Washington County. By contrast, the Secretary of State's list is much more comprehensive for nonlocal groups: it included six of the eight nonlocal groups in Addison County, and 32 of the 44 nonlocal groups in Washington County. All told, 61 of the 95 local groups in Addison County are not listed in any of the publicly available sources; 53 of the 90 local groups in Washington County are not so listed. By contrast, all but five of the nonlocal 
groups across the two counties are listed in at least one of the publicly available directories.

\section{Table 1 about here.}

This table, therefore, illustrates the systematic undercounting of local landbased groups by the best publicly available sources. One would have expected to find large nonlocal environmental groups that are actively soliciting taxdeductible donations in the official public lists: these include, for example, the Northern Forest Alliance, the Vermont Natural Resources Council, and the state chapter of the Nature Conservancy. Local groups, however, are infrequently listed: these include groups as diverse as 4-H chapters, the Route 2 Citizen’s Alliance, and the Friends of the Northfield Range. Without systematic prodding within each community, the majority of local land-based groups — and their influence in their communities and beyond—can easily go unnoticed. $^{10}$

\section{The Distribution of Autonomous Land-Based Groups and Chapters}

Table 2 illustrates the distribution of all 237 land-based groups in our census. The top half of the table shows that Addison County currently has 103 land-based groups. Thirty-four of the local agricultural groups are chapters: these include 27 chapters of 4-H and six chapters of the Grange. Only nine of the 19 local outdoor recreational groups, by contrast, are chapters; eight of these are town-level snowmobile clubs, organized in the state under the Vermont Association of Snow Travelers (VAST). The ten local autonomous outdoor recreational groups include groups as diverse as the Silver Streakers 
Biking Group and the Addison County Trail Blazers of all-terrain vehicle riders.

The contrast between autonomous groups and chapters is even more striking among the 41 local environmental groups in Addison County: only six of these are chapters, including the Otter Creek Audubon Society. The 35 local autonomous environmental groups include groups as diverse as the Lewis Creek Association, the Lake Dunmore/Fern Lake Association, and seven conservation commissions.

Finally, Addison County has eight nonlocal groups. Among these are four autonomous environmental groups (including Ecologia, which is an international-level group dedicated to supporting environmentally-oriented civic engagement) and two environmental chapters (including the Federated Garden Clubs of Vermont).

Table 2 about here.

The second half of Table 2 shows that Washington County, with 134 landbased groups, has a similar distribution among local groups. Fifteen of the 18 local agricultural groups are chapters, 15 of the 31 local outdoor recreational groups are chapters, but only nine of the 41 local environmental groups are chapters. The 32 local autonomous environmental groups in Washington County include, for example, the Friends of the Mad River Valley, the Capital Area Land Trust, and eight conservation commissions. In addition, 44 nonlocal groups are located in Washington County (35 of which are based in Montpelier). Thirty-seven are environmental groups, including state-level 
chapters such as the Vermont Land Trust and the Nature Conservancy of Vermont, and autonomous national-level groups such as the Noise Pollution Clearing House.

This table, therefore, illustrates that local environmental groups-in stark contrast to local agricultural groups-tend to be autonomous groups, not chapters. These autonomous local groups are truly community-based and hence a likely source of social capital. For instance, from September 1999 to September 2000, 180 volunteers participated in Lewis Creek Association (LCA) programs. The LCA has an active membership of 240, so approximately two-thirds of members interacted with each other in some way. ${ }^{11}$

Participation in such groups is clearly different from participation in the chapters of national environmental groups like the Sierra Club. Although the growth of these national groups has been impressive, members of their chapters have little interaction with other members. Nationwide, between 10 and 20 percent of Sierra Club members participate in any way: voting for board members, attending chapter or group meetings, or participating in outing or travel programs (Shaiko 1999:178).

\section{The History and Size of Land-Based Groups}

Table 3 details the founding dates and membership patterns of groups in our census. In this sub-section, we first draw attention to notable founding and membership trends among each type of local land-based group: agricultural, 
outdoor recreational, and environmental. We then consider the trends among the nonlocal groups.

\section{Table 3 about here.}

Local agricultural groups: The founding dates of existing agricultural groups are fairly evenly distributed across three distinct time periods—-pre1970, 1970-1985, and post 1985-but the distribution within this category is quite uneven. Thirteen of the 23 local agricultural groups founded in the two counties before 1970 are Grange chapters, and another seven are 4-H chapters. By contrast, 20 of the 21 local agricultural groups founded in the two counties since 1985 are 4-H chapters. According to this census, the 4-H, whose mission is "to enable young people to acquire knowledge, develop life skills and form attitudes that enable them to become self-directing, productive, and contributing members of society” (National 4-Headquarters 2002), has remained vibrant in these two counties.

This strength is confirmed by examining membership patterns among local agricultural groups. Of the 488 core members of local agricultural groups in Addison County, 389 are 4-H leaders and youth members; of the 1,288 total members, 589 are in the 4-H. The trend is less prominent in Washington County: 127 of the 241 comparable core members are 4-H leaders and youth members, as are 191 of the 757 total comparable members. (Given the relative prominence of dairy farming in Addison County, this difference is not unexpected.) 
Local outdoor recreational groups: The founding dates of existing local outdoor recreational groups are also fairly evenly distributed across the same three time periods, but among these groups the distribution is also quite uneven. Fourteen of the 18 local outdoor recreational groups founded in the two counties between 1970 and 1985 are chapters of VAST. This wave of founding of these snowmobile chapters can be directly attributed to state legislation passed in the early 1980s, which requires all snowmobile riders in Vermont to belong to VAST and to a local club to ride legally in the state. Currently, the 21 VAST chapters in our census include 272 core members and 3,922 total members.

By contrast, only one of the 17 current local outdoor recreational groups founded since 1985 is a VAST chapter. The other 16 groups include fishing, mountain biking, sailing, skiing, and trail running clubs. Currently, the 23 local outdoor recreational groups that are not VAST chapters include 492 core members and 3,676 total members, which include 282 core members and 1,706 total members of the 16 groups founded since 1985.

We believe that this rise in non-snowmobile oriented local outdoor recreational groups since 1985 is an important part of the greening of social capital that we document in this article, since participation in such outdoor recreational activities is likely to be associated with pro-environmental behavior (Theodori, Luloff, and Willits 1998).

Local environmental groups: The founding dates of existing local environmental groups are very skewed across the three-documented time 
periods. Of the 80 local environmental groups in our census, only six were founded before 1970, while 61 were founded since 1985. Within this category, there is also a marked contrast between the founding dates of autonomous groups and chapters. Among the 19 groups founded prior to 1985, 11 were local chapters of state or national groups (these include two local chapters of the Audubon Society, two Green Mountain Club chapters, and two chapters of Ducks Unlimited). Among the 61 groups founded since 1985, only four are chapters (all of which are chapters of Keeping Track, a relatively new statebased wildlife group). And among the 995 core members and 5,990 total members in local environmental groups in these two counties, 669 and 4,103 are, respectively, in groups that were founded since 1985.

These results are the empirical punch line of this article: since the mid1980s, the number and membership roles of local autonomous environmental groups has grown rapidly relative to local agricultural and outdoor recreational groups. Figure 1 illustrates the striking nature of this pattern. Of the 99 local land-based groups established since 1985, 62 percent are environmental. The pattern is quite similar in terms of membership. Sixty-five percent of the members of local land-based groups established since 1985 are in environmental groups. We believe that, for these two representative counties in Vermont, this provides the empirical evidence that Putnam felt was lacking in the United States (2000): “grassroots environmental activism” has indeed been rapidly growing in this part of the United States over the last 20 years.

Figure 1 about here. 
Nonlocal groups: As shown in the remaining sections of Table 3, only eight nonlocal agricultural and outdoor recreational groups are based in these two counties. The two most prominent are VAST, which oversees the network of local snowmobile chapters, and Rural Vermont, an agricultural and rural advocacy group with 3,000 statewide members.

By contrast, 41 nonlocal environmental groups are located in these counties, 25 of which have been founded since 1985. As illustrated by Figure 2, there has also been a rapid rise of nonlocal environmental groups relative to nonlocal agricultural and outdoor recreational groups.

Figure 2 about here.

These membership patterns in nonlocal environmental groups are very different than membership patterns in local environmental groups. Among the 534 core members and 59,424 total members of all nonlocal environmental groups, 235 and 52,457 are, respectively, in the 16 groups that were founded before 1985. Our data also show that the most prominent state-level groupsthe Vermont Public Interest Research Group (20,000 members), the Nature Conservancy of Vermont (7,500 members), and the Vermont Land Trust (7,500 members)-have built up their membership base over more than 30 years.

In many ways, the size of these groups emphasizes the different nature of membership in these nonlocal groups. We agree with Putnam (2000) that membership in these direct-mail organizations is not a good measure of social capital; the relative popularity of the older state-level groups is more an 
indication of their ability to rally sustained political support for environmental causes.

We conclude this section with a conceptual and empirical caveat. Our census comprises existing groups in Addison and Washington Counties, as of the summer of 2002. Since our data do not account for groups that no longer exist, we cannot fully assess the extended or recent history of the changing nature of land-based groups. First, we do not have information about historically prominent agricultural groups founded before 1970 that no longer exist; many local Grange chapters would fit this characterization. Second, we do not have information about any prominent former land-based groups founded after 1970 that no longer exist; this might include NIMBY or other kinds of environmental groups that were formed to deal with specific local environmental issues. Finally, we cannot compare the changing nature of landbased groups to all types of groups in these two counties (e.g., the Masons, the Jaycees, and the Independent Order of the Odd Fellows).

\section{Conclusion}

This article presents two major findings. First, the data suggest how the existence of many local environmental groups is easily missed. Second, the data demonstrates the changing nature of local land-based groups in Addison and Washington Counties: since the mid-1980s, the number and membership roles of local autonomous environmental groups have grown rapidly relative to all other types of local and nonlocal land-based groups in these counties. ${ }^{12}$ 
These results help illustrate several stories. First, the existence of so many (unlisted) local environmental groups may undermine some of Putnam's claims about the decline of social capital in the United States. If such findings are found elsewhere in the nation-as they have been in the Delmarva Peninsula and in North Carolina (Holland 2002; Kempton et al. 2001)-one may conclude that, throughout the nation, citizens who formerly joined the Rotary and the Kiwanis Clubs are now joining local environmental groups. ${ }^{13}$ Second, agricultural groups have clearly declined, while membership in nonsnowmobile recreational groups and environmental groups has increased dramatically. ${ }^{14}$

We believe that these two related trends may illustrate how the changing ways in which humans relate to the landscape has altered the nature of rural social capital. The story, we speculate, unfolds as follows. As recently as 30 years ago, the dominant land-based groups were agricultural. These groups, which had existed for generations, had a distinct social capital function: they bonded farmers and their families by pursuing a common economic selfinterest and by celebrating their common agricultural heritage. Today, this bonding social capital among like-minded farmers is being replaced by bridging social capital among a wide range of landowners. ${ }^{15}$ Networks and norms devoted to the economic self-interest of a few have been replaced by networks and norms devoted to conserving the natural resources of many. It is likely that such changes echo the larger economic shifts and changing values among the United States population (Dunlap 1992; Inglehart 1990). Although 
our study focuses on a small geographic area, we believe that our understanding of these changes applies to other parts of rural America, such as the Pacific Coast, Rocky Mountains, Southwest, Upper Midwest, Southern Appalachian Highlands, and northern New England. Furthermore, we surmise that such local environmental groups are most common in vibrant rural areas, where people have a closer connection to the landscape than in suburbs or urban areas. This article reports the first set of evidence necessary to verify this story.

We believe that the economic and political implications of this sociological switch are underappreciated and large. In the last two decades, local environmental groups have played an increasingly important role in promoting community sustainability, in diverse areas such as water monitoring and wildlife habitat identification, the purchase of land and conservation easements, and the prevention of the location of unwanted environmental harms in communities (sometimes derogatively referred to as NIMBYism) (Gottlieb 1993; Press 2002; Wild Earth 2001-2002). As national- and (increasingly) state-level politics become professionalized and the purview of big money, citizens are increasingly turning to local groups to engage in democratic politics. Democratic theorist John Dryzek points to public spheres in civil society as one of the few places where democracy, faced with the constraints of economic rationality and the international system, can expand today (1996). The evidence presented in this article sheds light on the rising role of local land-based groups in this process. 


\section{References}

Barron, H.S. 1984. Those Who Stayed Behind: Rural Society in NineteenthCentury New England. New York: Cambridge University Press.

Castle, E.N. 2002. “Social Capital: An Interdisciplinary Concept.” Rural Sociology 67: 331-49.

Dryzek, J.S. 1996. Democracy in Capitalist Times: Ideals, Limits, and Struggles. New York: Oxford University Press.

Dunlap, R.E. 1992. “Trends in Public Opinion Toward Environmental Issues: 1965-1990.” Pp. 89-116 in American Environmentalism, edited by R.E. Dunlap and A.G. Mertig. Philadelphia: Taylor and Francis.

Ervin, J. 2002. “Community-based Conservation Planning at a Watershed Scale: Three Vermont Case Studies and Their Implications for Planning Theory.” PhD dissertation, College of Natural Resources, University of Vermont.

Glaeser E.L., D. Laibson, J.A. Scheinkman, and C.L. Soutter. 2000. “Measuring Trust.” Quarterly Journal of Economics 65:811-846.

Gottlieb, R. 1993. Forcing the Spring: The Transformation of the American Environmental Movement. Washington: Island Press.

Grønberg, K. and L. Paarlberg. 2001. “Community Variations in the Size and Scope of the Nonprofit Sector: Theory and Preliminary Findings.” Nonprofit and Voluntary Sector Quarterly 30:684-706. 
Holland, D. 2002. “Not-for-Profit Visions of the Public Good: Activism and Democracy in North Carolina.” Department of Anthropology. University of North Carolina, Chapel Hill. Unpublished manuscript.

Inglehart, R. 1990. Culture Shift in Advanced Industrial Society. Princeton, NJ: Princeton University Press.

Institute for Southern Studies. 2002. “Gold and Green 2000.” Retrieved August 6, 2002. (http://www.southernstudies.org/).

Isham, J. and J. Polubinski. 2002. "Killington Mountain Resort: A Case Study of ‘Green’ Expansion in Vermont.” Vermont Law Review 26:565-591.

Judd, R.W. 1997. Common Lands, Common People: The Origins of Conservation in Northern New England. Cambridge, MA: Harvard University Press.

Kempton, W., D.C. Holland, K. Bunting-Howarth, E. Hannan, and C. Payne. 2001. "Local Environmental Groups: A Systematic Enumeration in Two Geographical Areas.” Rural Sociology 66:557-578.

Kimberly, G. 2002. “2002 Portrait of Vermont’s Charitable Sector.” Vermont Alliance of Nonprofit Organizations, Burlington, VT. Unpublished manuscript.

Klyza, C.M. and S.C. Trombulak. 1999. The Story of Vermont: A Natural and Cultural History. Hanover, NH: University Press of New England.

Knack, S. 2002. "Social Capital and the Quality of Government: Evidence from the U.S. States.” American Journal of Political Science 46:772-85. 
Lester, J.P. 1994. “A New Federalism? Environmental Policy in the States.” Pp. 51-68 in Environmental Policy in the 1990s, 2d ed., edited by N.J. Vig and M.E. Kraft. Washington: CQ Press.

Lubell, M., M. Schneider, J.T. Scholz, and M. Mete. 2002. “Watershed Partnerships and the Emergence of Collective Action Institutions.” American Journal of Political Science 46:148-63.

Narayan, D. and L. Pritchett. 1999. "Cents and Sociability: Income and Social Capital in Rural Tanzania.” Economic Development and Cultural Change 47:871-97.

National 4-Headquarters. 2002. Retrieved October 24, 2002. (http://www.4husa.org/4h_faq.htm).

Press, D. 2002. Saving Open Space: The Politics of Local Preservation in California. Berkeley and Los Angeles: University of California Press.

Putnam, R.D. 1993. Making Democracy Work: Civic Traditions in Modern Italy. Princeton, NJ: Princeton University Press.

Putnam, R.D. 2000. Bowling Alone: The Collapse and Revival of American Community. New York: Simon and Schuster.

Savage, A., J. Isham, and C.M. Klyza. 2002. "The Transformation of Social Capital in Vermont.” Presented at the annual meetings of the New England Political Science Association, May 4, Portland, ME.

Shaiko, R.G. 1999.Voices and Echoes for the Environment: Public Interest Representation in the 1990s and Beyond. New York: Columbia University Press. 
Skocpol, T., M. Ganz, and Z. Munson. 2000. “A Nation of Organizers: The Institutional Origins of Civic Voluntarism in the United States.” American Political Science Review 94:527-46.

Smith, D.H. 2000. Grassroots Associations. Thousand Oaks, CA: Sage Publications.

Theodori, G.L., A.E. Luloff, and F.K. Willits. 1998. “The Association of Outdoor Recreation and Environmental Concern: Reexamining the DunlapHeffernan Thesis.” Rural Sociology 63: 94-108.

Vermont Natural Resources Council. 2000. Vermont Environmental Directory. Montpelier, VT: VNRC.

Vermont Peace and Justice Center. 2002. Vermont Grassroots Directory, 3d ed. Burlington, VT: VPJC.

Wild Earth. 2001-2002. Issue devoted to citizen science. Fall/winter.

Woolcock, M. 2002. "Social Capital in Theory and Practice: Where Do We Stand?” Pp. 18-39 in Social Capital and Economic Development: WellBeing in Developing Countries, edited by J. Isham, T. Kelly, and S. Ramaswamy. Chetlenham, UK: Edward Elgar Publications.

Wollebaek, D., and P. Selle. 2002. "Does Participation in Voluntary Associations Contribute to Social Capital? The Impact of Intensity, Scope, and Type.” Nonprofit and Voluntary Sector Quarterly 31:32-61. 
Table 1: Publicly Available Lists of Land-Based Groups in Addison and Washington Counties

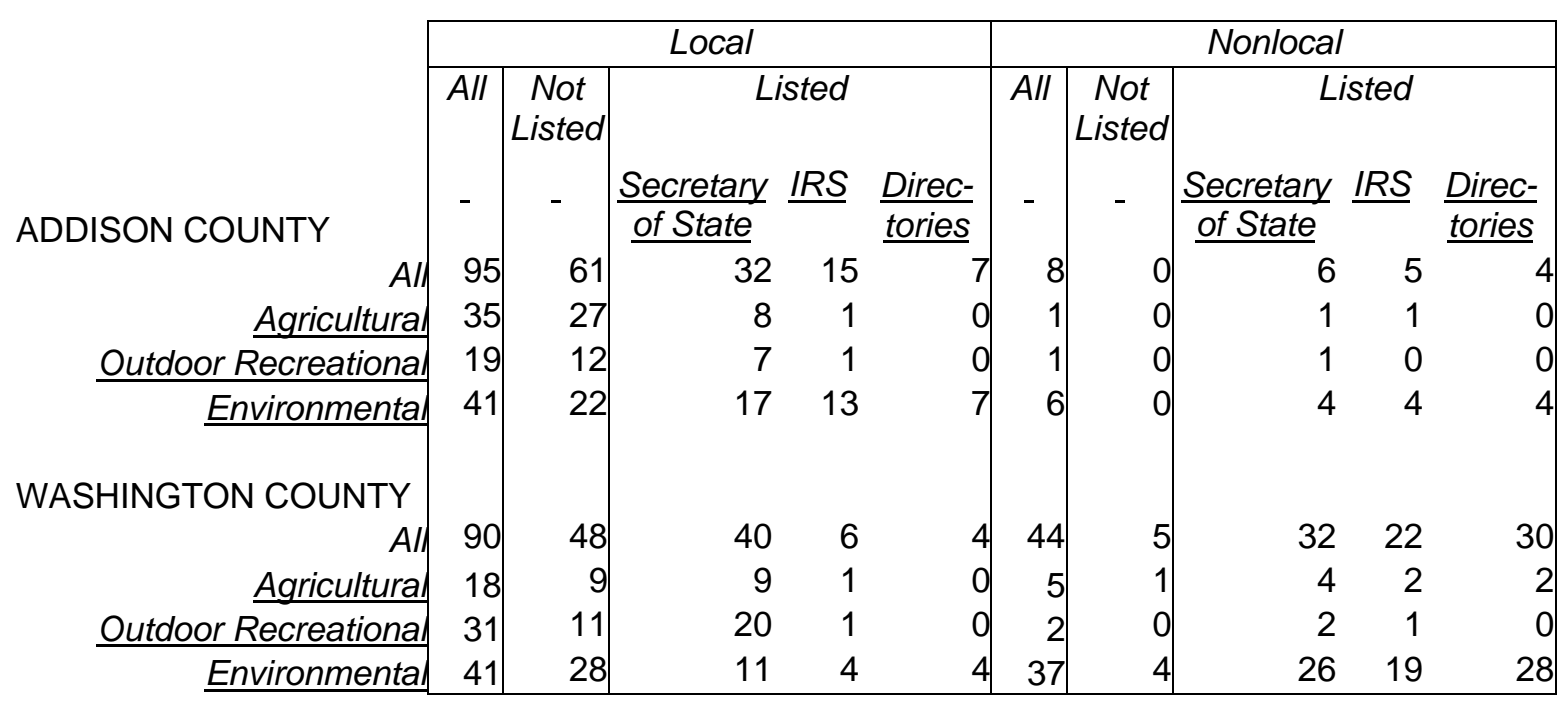

Note: See text for definitions of classifications. 
Table 2: Distribution of Land-Based Groups in Addison and Washington Counties

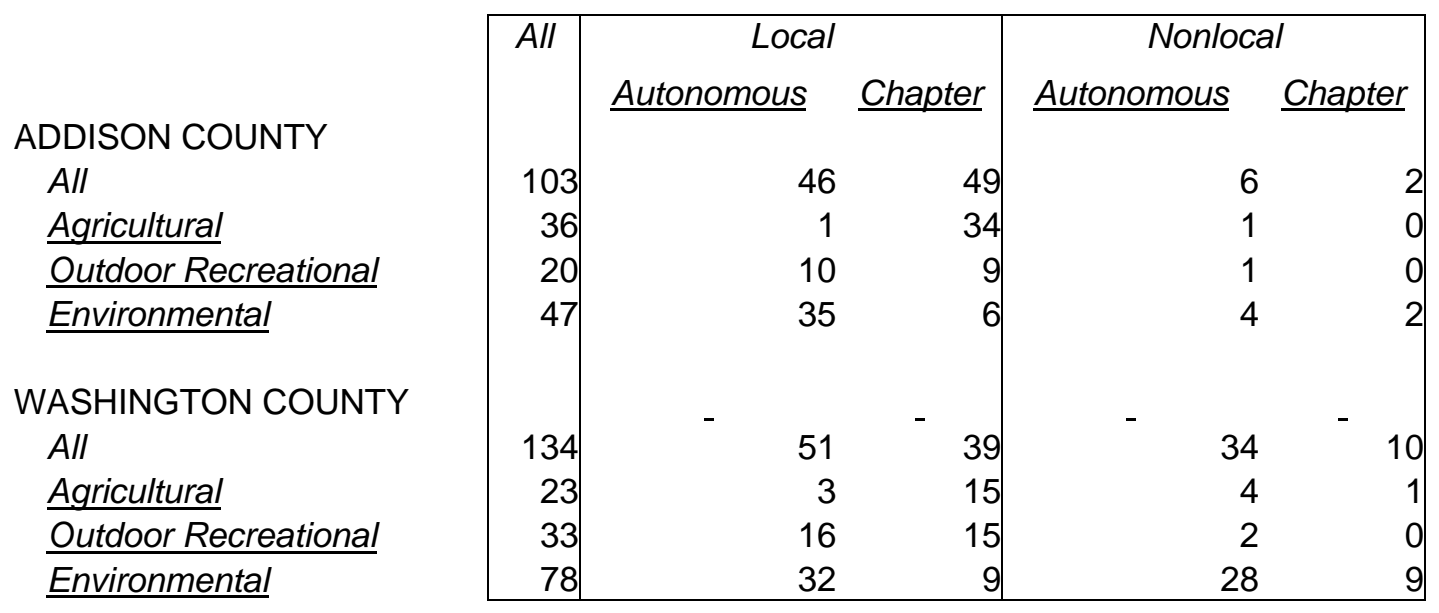

Note: See text for definitions of classifications. 
Table 3: The Composition of Land-Based Groups in Addison and Washington Counties

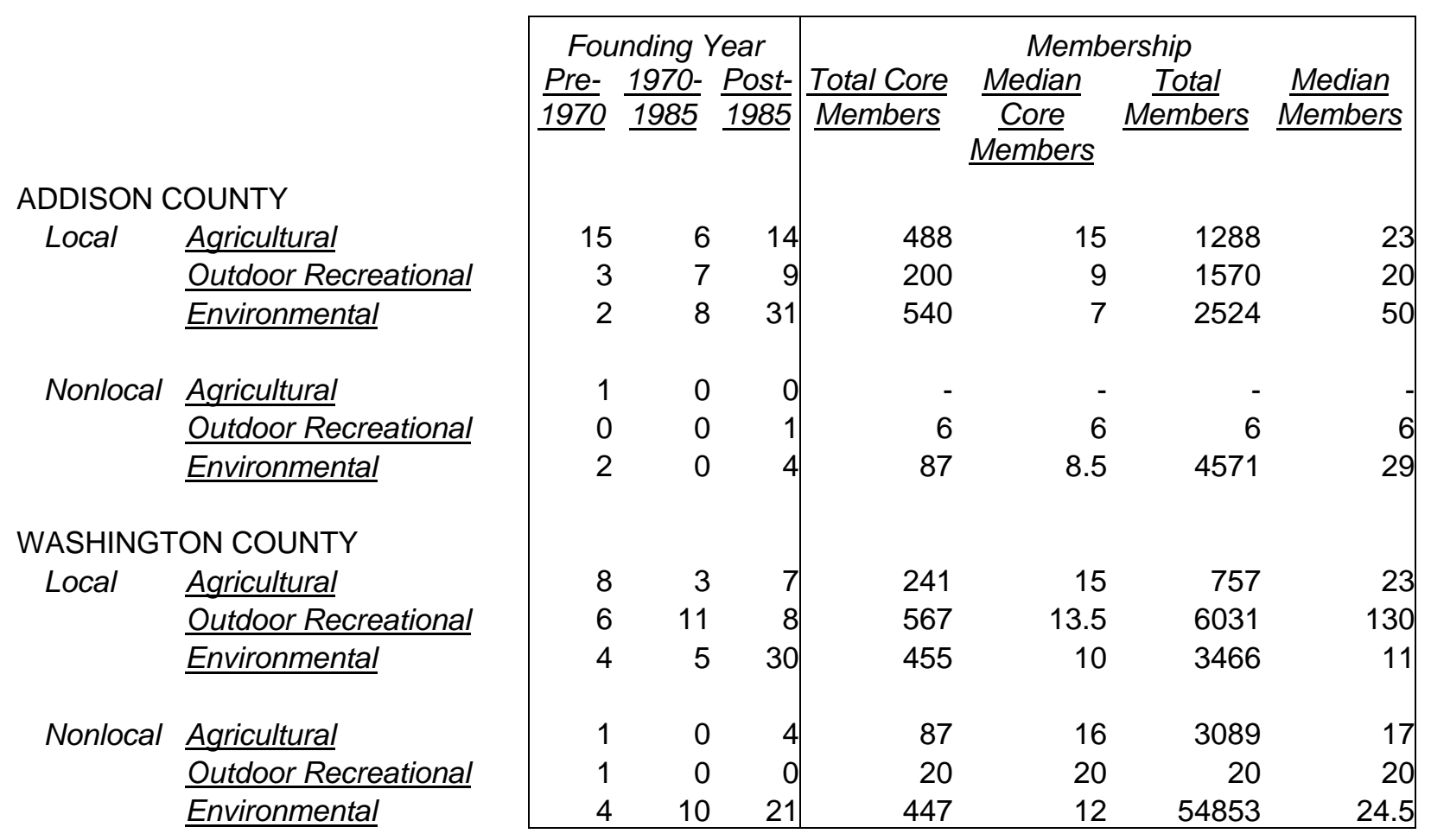

Note: See text for definitions of classifications. 
Figure 1: The Founding Dates of Local Land-Based Groups: Addison and Washington Counties

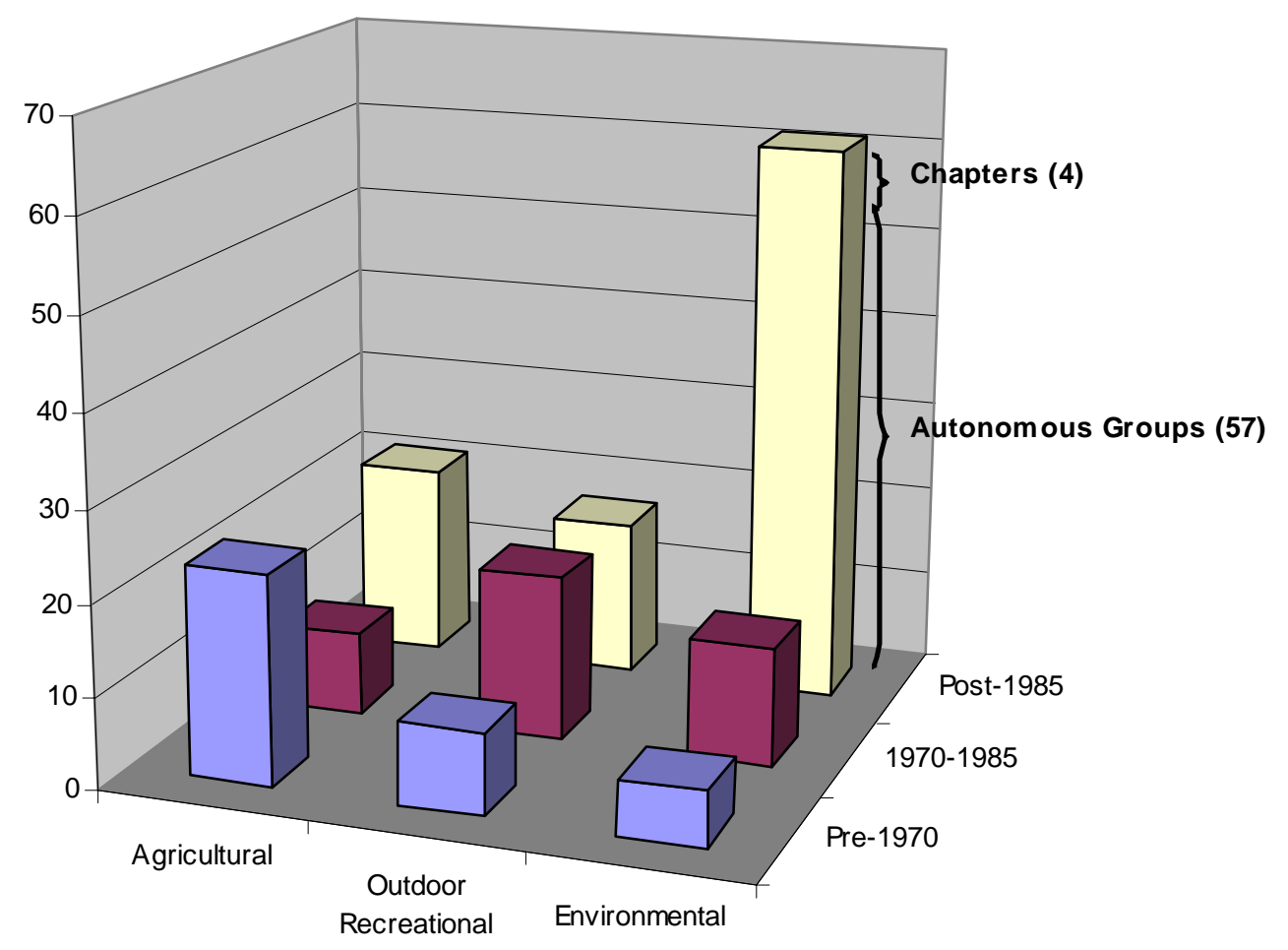


Figure 2: The Founding Dates of Nonlocal Land-Based Groups: Addison and Washington Counties

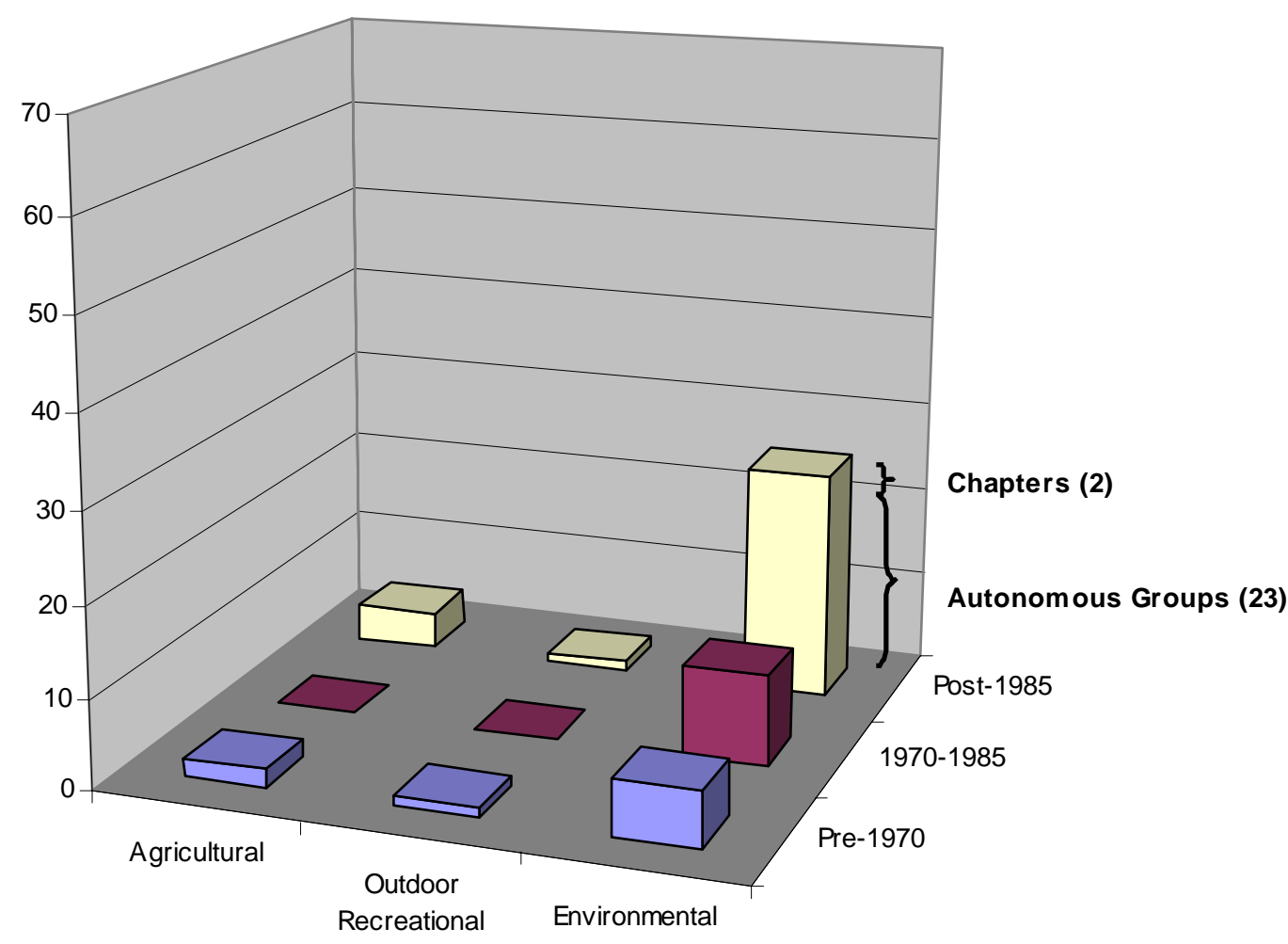

${ }^{1}$ Future work will examine how norms and networks facilitate collective action and "the interdependence of forms of autonomous social capital and the attainment of public policy objectives” (Castle 2002:339).

${ }^{2}$ Since it is exceedingly difficult to measure social networks and norms even with an extensive survey (e.g., Glaeser et al. 2000), many prominent scholars in this area have used measures of the quantity and quality of local associations as one means of empirically assessing the formation and 
effects of different forms of social capital (e.g., Knack 2002; Narayan and Pritchett 1999; Putnam 1993). In the research reported here, we make no effort to measure norms.

${ }^{3}$ The other nine variables include measures of engagement in public affairs (two), measures of community volunteerism (three), measures of informal sociability (two), and measures of social trust (two) (Putnam 2000:291).

${ }^{4}$ Ervin documents the large influence of keystone individuals among community-based conservation planning groups in Vermont, who "have multiple conservation-related affiliations within their communities and within their professional lives” (Ervin 2002:109).

${ }^{5}$ The basic municipa1 unit in Vermont is the town. The state is divided into 249 such towns, some of which feature one or more villages. Our research focused on all of the towns within Addison and Washington Counties.

${ }^{6}$ On the related concept of grassroots groups, see Smith (2000).

${ }^{7}$ We include conservation commissions in this category, since each local conservation commission, while statutorily authorized by state law, is not subject to the by-laws of a larger organization. In most cases, the structure of these groups is completely shaped by local conditions.

${ }^{8}$ Our methodology was similar to those documented in Grønberg and Paarlberg (2001), Kempton et al. (2001), and Smith (2000).

${ }^{9}$ 501(3)c refers to the Internal Revenue Service code for groups that are registered as nonprofit organizations and that can receive tax-deductible donations.

${ }^{10}$ Our findings in this regard are not as striking as those of Kempton et al. (2001), who found that the actual number of groups in the Delmarva Peninsula and the state of North Carolina were seven to 20 times the number reported in the best published directories. 
${ }^{11}$ The LCA, an autonomous local group founded in 1990, is defined by the watershed of the Lewis Creek in Vermont's northern Addison and southern Chittenden Counties. Of the 1,700 residences in the Lewis Creek watershed, approximately 40 percent are included on LCA's mailing list. In 2000, 171 residences (including 240 individual names)_just over 10 percent of the watershed's population-donated money to LCA.

${ }^{12}$ Our future research plans are to census all groups in the history of 11 representative towns in these counties, thereby allowing us to compare the changing nature of landbased groups to changes in all types of groups in this rural area over the last two centuries.

${ }^{13}$ These findings would run counter to another Putnam conclusion: that "place-based social capital is being supplanted by function-based social capital” (2000:184).

${ }^{14}$ This decline in Vermont, a mature agricultural region, may foreshadow similar declines in other agricultural and rural parts of the nation. In fact, these changes are similar to earlier transitions to Vermont’s agricultural economy and migration patterns of the middle nineteenth century (Barron 1984).

15 The terms bonding and bridging are conceptualized by Putnam. Bonding social capital, which refers to networks and norms among family members, close friends, and neighbors, is inward looking and reinforces exclusive identities and homogenous groups. Bridging social capital, which refers to networks and norms among more distant associates and colleagues, is outward looking and encompasses people across diverse social cleavages (Putnam 2000). 
